\title{
Simulation Study on the Dynamic Behaviors of Water-in-Oil Emulsified Droplets on the Coalescing fibers
}

Chaolang Chen, Lei Chen, Ding Weng, Xuan Li, Zhaoxin Li, Jiadao Wang*

State Key Laboratory of Tribology, Tsinghua University, Beijing 100084, P.R. China

*Corresponding author: jdwang@mail.tsinghua.edu.cn

Number of page: 5

Number of figures: 6

Number of tables: 1

\section{Contents:}

1. Wetting behaviors of a underoil water droplet on a cylinder (Figure S1)

2. The effects of inlet velocity on the dynamic behaviors of droplet on a single fiber (Figure S2)

3. Position variations of the droplet on the fiber surface with tilt angle of $75^{\circ}$ (Figure

4. Control group: the stationary state of droplet on two angled fibers (Figure S4)

5. The effects of inlet velocity on the detachment behaviors of droplet (Figure S5)

6. The effects of fibers surface wettability on the detachment behaviors of droplet (Figure S6)

7. The physical properties of the water phase and the oil phase are used in the simulation models (Table S1) 

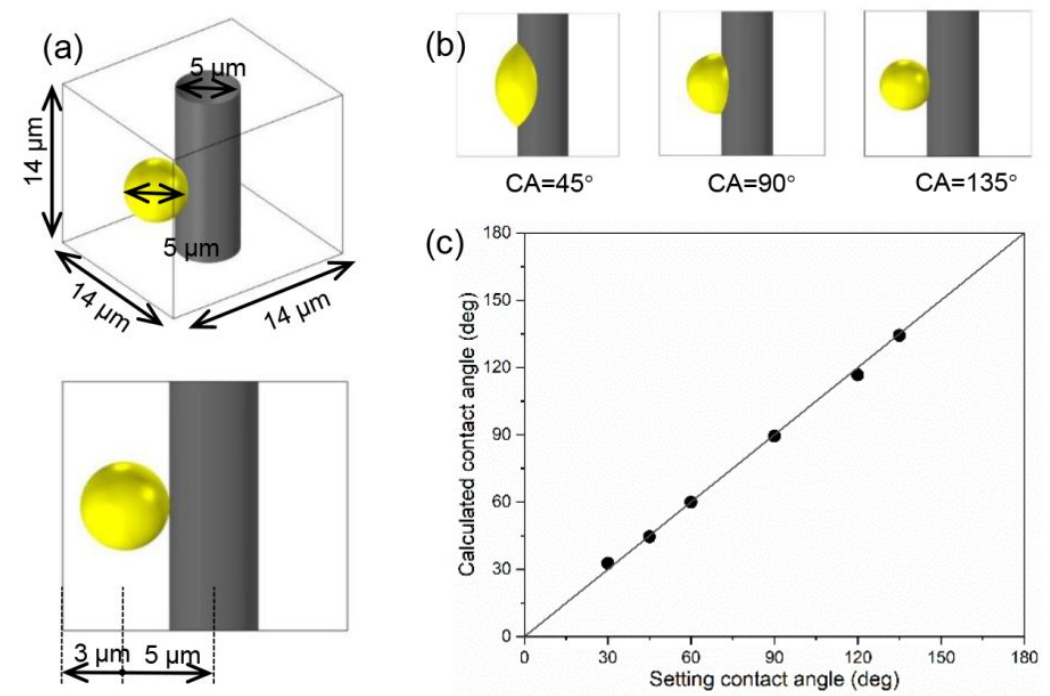

Figure S1. Wetting behaviors of a droplet on a cylinder with different wettability: (a) computational domain and initial set up. (b) Snapshots of the droplet reaching an equilibrium state for a contact angle of $45^{\circ}, 90^{\circ}$, and $135^{\circ}$, and (c) simulated contact angles as a function of setting contact angles.
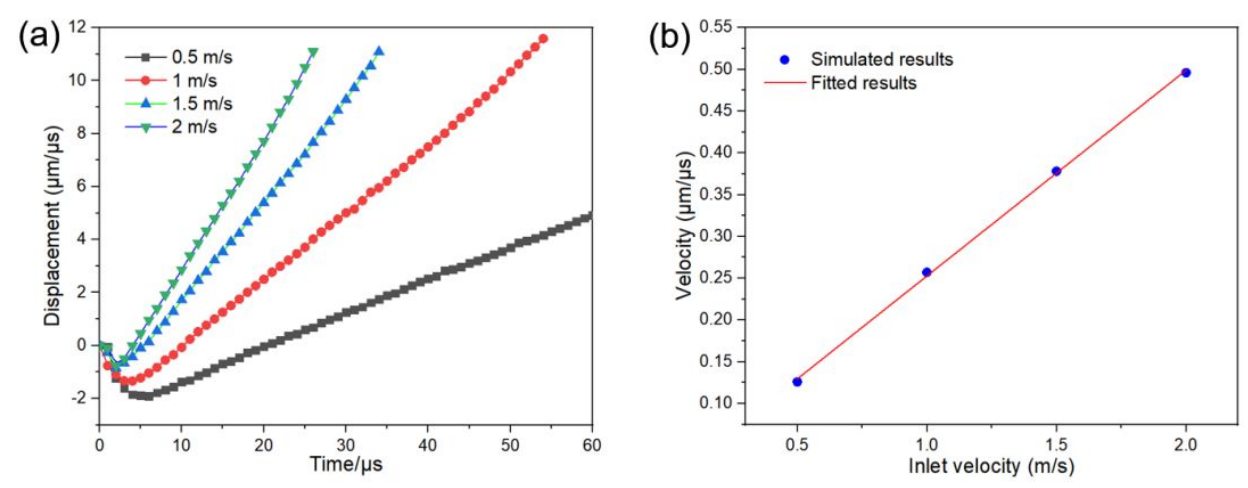

Figure S2. (a) Time variations of the displacement curve of $5 \mu \mathrm{m}$ droplet on the fiber at different inlet velocity, that is, $0.5 \mathrm{~m} / \mathrm{s}, 1 \mathrm{~m} / \mathrm{s}, 1.5 \mathrm{~m} / \mathrm{s}$, and $2 \mathrm{~m} / \mathrm{s}$; (b) shows the velocity variations of the droplets over different inlet velocity (simulation parameters: fiber surface contact angle: $90^{\circ}$; tilt angle: $45^{\circ}$ ). 

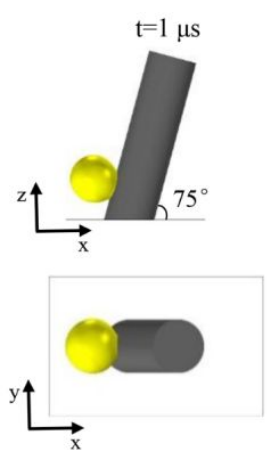
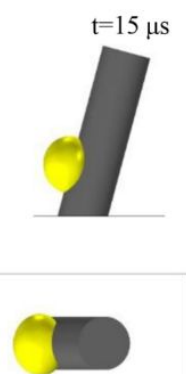
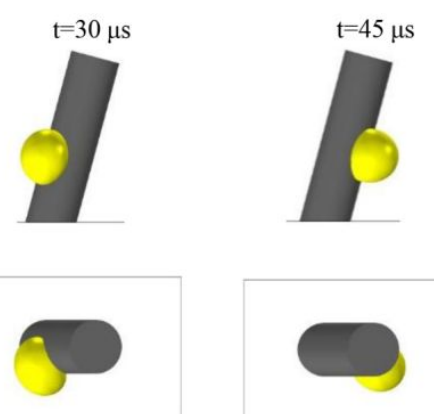
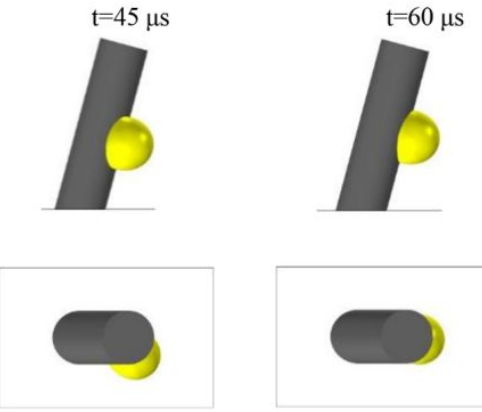

Figure S3. Position variations of the droplet on the fiber surface over time. (Operation parameters: tilt angle: $75^{\circ}$; inlet speed: $1 \mathrm{~m} / \mathrm{s}$; contact angle: $90^{\circ}$ )
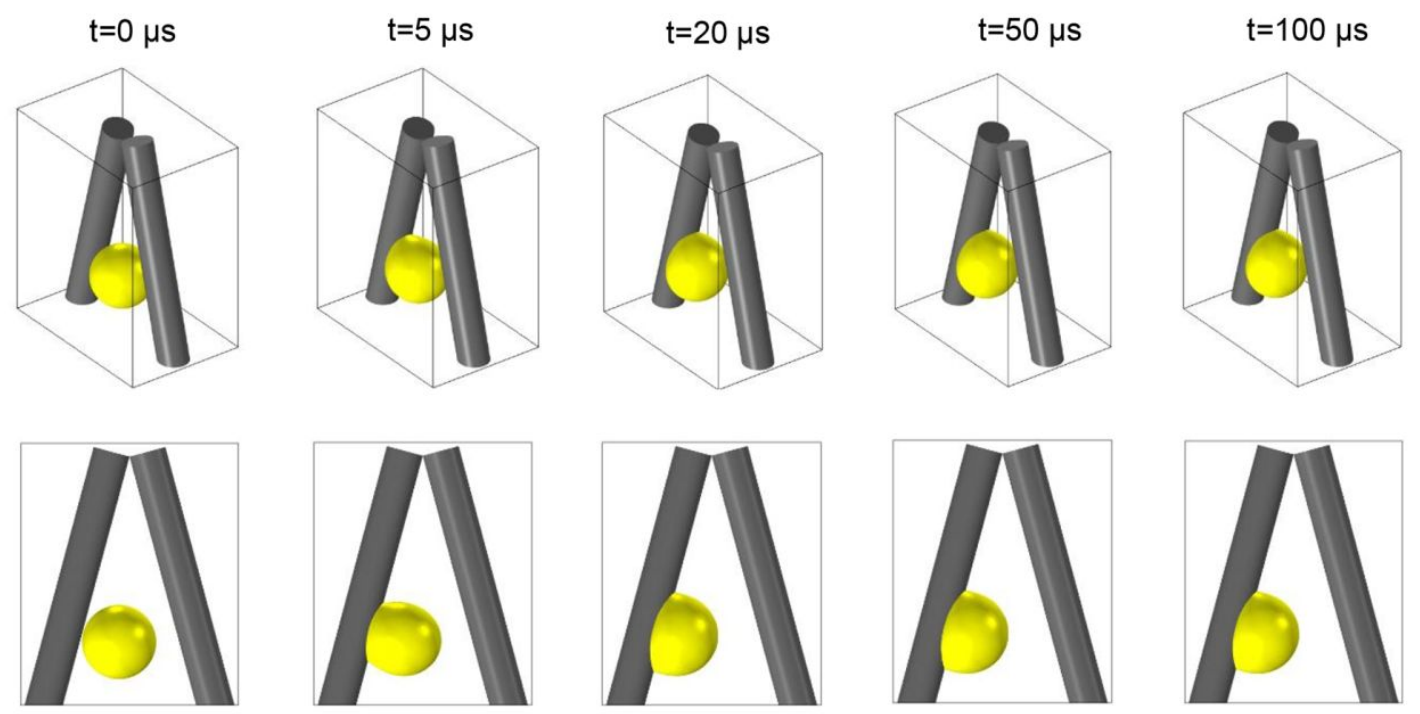

Figure S4. Control group: the initial position of the droplet was far away from one of the fibers, the liquid bridge could not be formed between the fibers, which resulted in a stationary droplet attached to the fiber. 


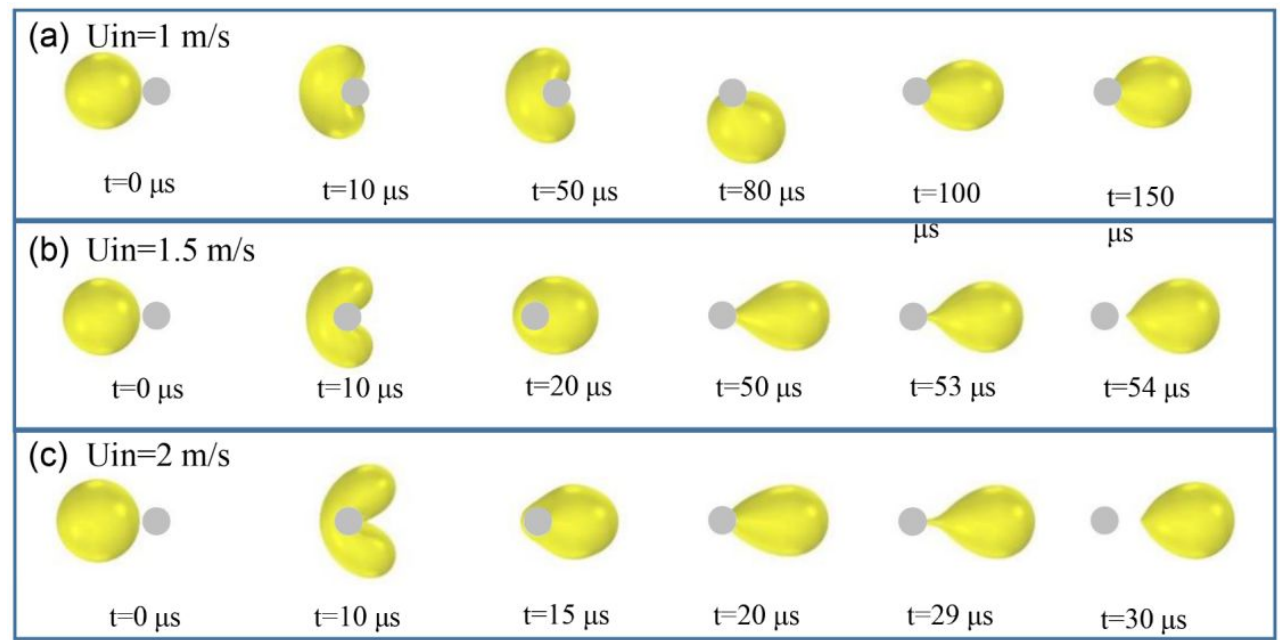

Figure S5. The effects of inlet velocity on the detachment behaviors of droplet from single fiber surface: (a) $1 \mathrm{~m} / \mathrm{s}$, (b) $1.5 \mathrm{~m} / \mathrm{s}$, (c) $2 \mathrm{~m} / \mathrm{s}$. (Simulation parameters: contact angle is $90^{\circ}$, droplet diameter is $15 \mu \mathrm{m}$, fiber diameter is $5 \mu \mathrm{m}$ )

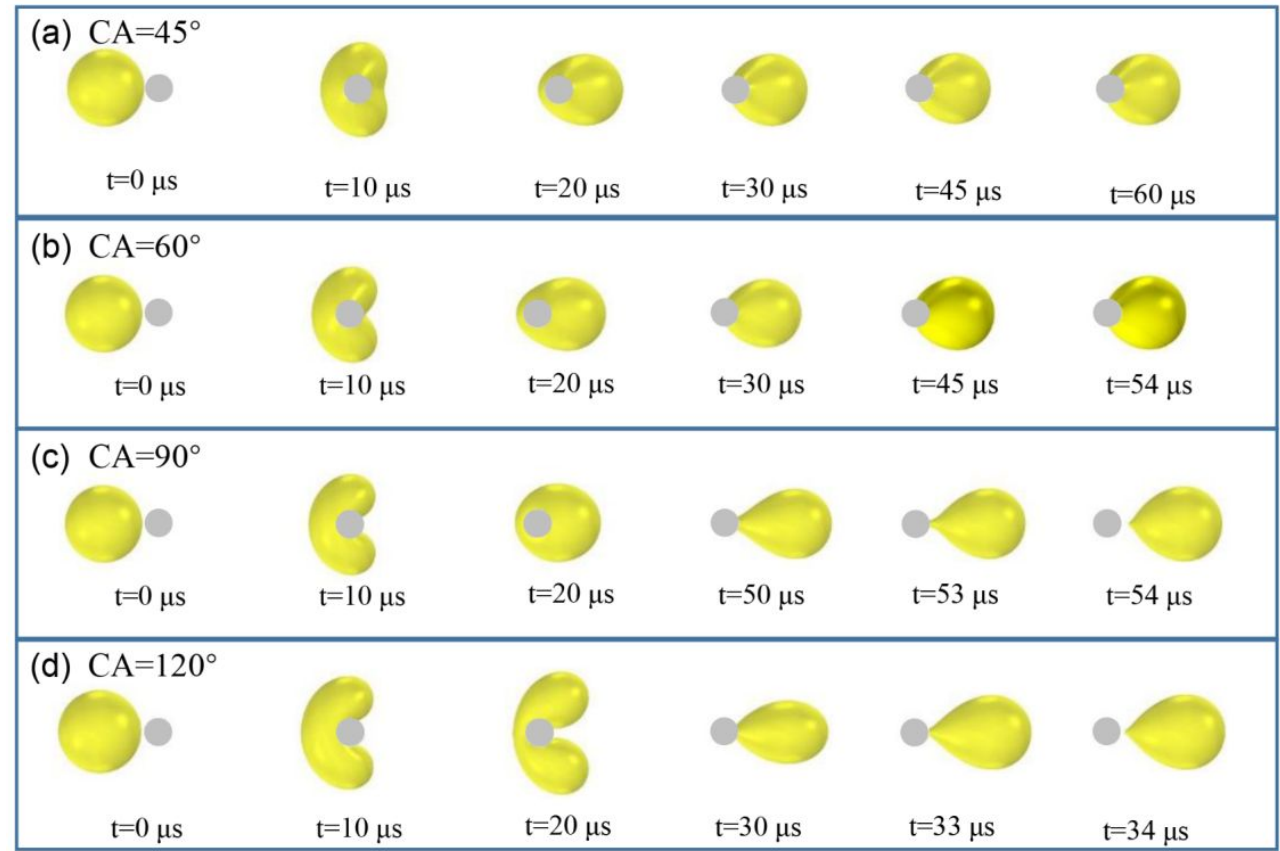

Figure S6. The effects of fibers surface wettability on the detachment behaviors of the droplet from single fiber surface: (a) $45^{\circ}$, (b) $60^{\circ}$, (c) $90^{\circ}$, (d) $120^{\circ}$. (Simulation parameters: inlet velocity is $1.5 \mathrm{~m} / \mathrm{s}$, droplet diameter is $15 \mu \mathrm{m}$, fiber diameter is $5 \mu \mathrm{m}$ ) 
Table S1. The physical properties of the water phase and the oil phase are used in the simulation models.

\begin{tabular}{|l|l|l|}
\hline & Water phase & Oil phase \\
\hline Density $/ \mathrm{kg} \cdot \mathrm{m}^{-3}$ & 998.2 & 750.0 \\
\hline Viscosity $/ \mathrm{Pa} \cdot \mathrm{s}$ & 1 & 1.34 \\
\hline Interfacial tension $/ \mathrm{mN} / \mathrm{m}$ & \multicolumn{2}{|c|}{52.8} \\
\hline
\end{tabular}

